\title{
Evaluation of a real-time quantitative PCR to measure the wild Plasmodium falciparum infectivity rate in salivary glands of Anopheles gambiae
}

Alexandra Marie ${ }^{1 *}$, Anne Boissière ${ }^{1}$, Majoline Tchioffo Tsapi ${ }^{1,2}$, Anne Poinsignon ${ }^{1}$, Parfait H Awono-Ambéné2, Isabelle Morlais ${ }^{1,2}$, Franck Remoue ${ }^{1,3}$ and Sylvie Cornelie , $^{1,3}$

\begin{abstract}
Background: Evaluation of malaria sporozoite rates in the salivary glands of Anopheles gambiae is essential for estimating the number of infective mosquitoes, and consequently, the entomological inoculation rate (EIR). EIR is a key indicator for evaluating the risk of malaria transmission. Although the enzyme-linked immunosorbent assay specific for detecting the circumsporozoite protein (CSP-ELISA) is routinely used in the field, it presents several limitations. A multiplex PCR can also be used to detect the four species of Plasmodium in salivary glands. The aim of this study was to evaluate the efficacy of a real-time quantitative PCR in detecting and quantifying wild Plasmodium falciparum in the salivary glands of An. gambiae.

Methods: Anopheles gambiae ( $n=364$ ) were experimentally infected with blood from $P$. falciparum gametocyte carriers, and $P$. falciparum in the sporozoite stage were detected in salivary glands by using a real-time quantitative $P C R(q P C R)$ assay. The sensitivity and specificity of this $\mathrm{QPCR}$ were compared with the multiplex PCR applied from the Padley method. CSP-ELISA was also performed on carcasses of the same mosquitoes.

Results: The prevalence of $P$. falciparum and the intensity of infection were evaluated using $\mathrm{QPCR}$. This method had a limit of detection of six sporozoites per $\mu \mathrm{L}$ based on standard curves. The number of $P$. falciparum genomes in the salivary gland samples reached 9,262 parasites/ $\mu \mathrm{L}$ (mean: 254.5; 95\% Cl: 163.5-345.6). The qPCR showed a similar sensitivity (100\%) and a high specificity (60\%) compared to the multiplex PCR. The agreement between the two methods was "substantial" $(K=0.63, P<0.05)$. The number of $P$. falciparum-positive mosquitoes evaluated with the qPCR (76\%), multiplex PCR (59\%), and CSP-ELISA (83\%) was significantly different $(P<0.005)$.

Conclusions: The GPCR assay can be used to detect $P$. falciparum in salivary glands of An. gambiae. The $\mathrm{QPCR}$ is highly sensitive and is more specific than multiplex PCR, allowing an accurate measure of infective An. gambiae. The results also showed that the CSP-ELISA overestimates the sporozoite rate, detecting sporozoites in the haemolymph in addition to the salivary glands.
\end{abstract}

Keywords: Plasmodium falciparum, Anopheles gambiae, Salivary Glands, Quantitative PCR, Multiplex PCR, CSP-ELISA

\footnotetext{
* Correspondence: alexandra.marie@ird.fr

'Laboratoire MIVEGEC (UMR IRD 224 CNRS 5290 UM1-UM2), 911 Av.

Agropolis, 34394 Montpellier Cedex 5, France

Full list of author information is available at the end of the article
} 


\section{Background}

In malaria endemic countries, Plasmodium falciparum is transmitted to the human host by the bite from a female Anopheles mosquito. Anopheles gambiae sensu stricto (s.s.) is the most widespread malaria vector throughout the afrotropical belt. In the context of malaria eradication, it is essential for malaria-surveillance programmes to estimate accurately the risk of malaria transmission. Currently, the main indicator of Plasmodium transmission is the measure of the entomological inoculation rate (EIR) [1], which is the number of infective mosquito bites per human per night. In field settings, the EIR is commonly estimated by using captured adult mosquitoes. Evaluation of infection prevalence in salivary glands can be measured by counting sporozoites by microscopy [2] or by using the enzymelinked immunosorbent assay on the head-thorax of the mosquito to detect the surface circumsporozoite protein (CSP-ELISA) [3]. Both methods are known to be labour intensive and it has been shown that CSP-ELISA overestimates the real infection rate by detecting the CSP from the oocysts bursting, two to three days before the sporozoites actually reach the salivary glands $[2,4]$.

Research efforts in recent decades have led to the development of molecular biology tools for detecting Plasmodium falciparum in human blood [5] and in mosquito samples [6]. Among these, a multiplex PCR was developed by Padley et al to detect the four major species of Plasmodium (P. falciparum, Plasmodium malariae, Plasmodium ovale, and Plasmodium vivax) in human blood samples [7] and was applied to detect them in Anopheles mosquitoes. Multiplex PCR is based on the detection of a Small SubUnit of ribosomal RNA (SSU rRNA) of each Plasmodium species but it requires a significant amount of parasite DNA, which is not easily achieved with small tissues like a single pair of salivary glands. Specific and sensitive methods such as quantitative PCR (qPCR) have also been developed to measure the prevalence and intensity of infection in human blood samples [8,9]. In mosquito samples, quantification of $P$. falciparum oocysts in Anopheles stephensi [10] and in wild An. gambiae s.s. [11] has also been achieved through real-time PCR. The latter study evaluated the difference in susceptibility of malaria infection (oocyst stage) between the $\mathrm{M}$ and $\mathrm{S}$ molecular form of An. gambiae s.s. in Cameroon. In addition, Vernick et al [12] estimated the infection prevalence of $P$. falciparum (parasite culture) in An. gambiae (insectaryreared mosquitoes) by reverse transcriptase PCR using specific sequences of the Small SubUnit of ribosomal RNA (SSU rRNA) of the sporogonic stages. Recently, a duplex real-time PCR was developed for the detection of the four Plasmodium species in field mosquitoes from Benin based on species-specific primers and probes for the gene encoding the small subunit (18S) of Plasmodium rRNA [13]. However, in this study, the use of the head- thorax of mosquitoes leads to an inaccurate estimation of the EIR, which should be based only on the sporozoites present in salivary glands.

Therefore, it is important to develop sensitive and rapid diagnostic tools for detecting Plasmodium in salivary glands of the Anopheles vectors, as this will reveal the true proportion of infective mosquitoes and, consequently, only those that can transmit malaria parasites. The aim of the present study was to evaluate the sensitivity and the specificity of a quantitative PCR method in the detection of wild P. falciparum sporozoites in $A n$. gambiae salivary glands. First, the qPCR assay based on the mitochondrial cytochrome $\mathrm{c}$ oxydase subunit 1 (COX-1) gene described by Boissiere et al [11] was tested on infected salivary glands to detect and quantify $P$. falciparum. A comparison of the $\mathrm{qPCR}$ method with a multiplex PCR based on the Padley method was also made to identify the most sensitive method. Finally, a comparison of the infectivity rates obtained with these two techniques with those obtained with the CSP-ELISA was performed on the carcasses of mosquitoes without salivary glands. CSP-ELISA was considered the current reference method used in the field. In this paper, experiments were conducted in semi-field conditions. Anopheles gambiae mosquitoes were fed on blood from asymptomatic children containing high similar gametocyte densities (from 52.7 to 60.6 gametocytes $/ \mu \mathrm{L}$ ). In natural settings, mosquito infectivity rate depends on several factors such as gametocyte density, sex ratio and multiclonality of parasites [14-17]. In consequence, this original approach allowed to mimic field conditions, and thereby to evaluate the potential application of this qPCR in field settings. Data showed that qPCR is highly sensitive but more specific than the multiplex PCR. Moreover, this study confirmed that the CPS-ELISA overestimates the infectivity rate by detecting the circulating sporozoites in addition to those present in salivary glands.

\section{Methods}

\section{Ethics statements}

All procedures involving human subjects used in this study were approved by the Cameroonian National Ethical Committee (statement 099/CNE/SE/09). Children identified as gametocyte carriers were enrolled as volunteers after their parents or legal guardians have signed an informed consent form.

\section{Mosquito collection}

The Kisumu strain of An. gambiae was provided by the Laboratoire de Lutte contre les Insectes Nuisibles, Institut de Recherche pour le Développement, France. The colony was established and maintained at the insectary in OCEAC (Yaoundé, Cameroon) for the experimental infections. Adult mosquitoes were maintained in 
standard insectary conditions $\left(27 \pm 2^{\circ} \mathrm{C}, 85 \pm 5 \% \mathrm{RH}\right.$, and $12 \mathrm{~h} \mathrm{light/dark)}$ and provided with $6 \%$ sterile sucrose solution.

\section{Experimental infections and salivary gland dissection} Female mosquitoes were fed on $P$. falciparum gametocyte carriers. Infectious feeding was performed as previously described $[18,19]$. Females, three to five days old, were starved for $24 \mathrm{~h}$ and allowed to feed on human blood containing $P$. falciparum gametocytes for $35 \mathrm{~min}$. Unfed and partially fed mosquitoes were removed by aspiration and discarded. Fully engorged females were kept in the insectary until dissections 14 days after the infectious blood meal. Mosquitoes were cold-anaesthetized and salivary glands were dissected in $10 \mu \mathrm{L}$ of buffer containing $7 \mathrm{M}$ urea, $2 \mathrm{M}$ thiourea, and 4\% CHAPS (GE, Healthcare). Samples were kept frozen individually at $-20^{\circ} \mathrm{C}$ until processing.

\section{CSP-ELISA assay}

After the dissection of salivary glands, the carcassthorax-head were tested by ELISA for the presence of $P$. falciparum CSP as described by Burkot and modified by Wirtz et al [20]. The monoclonal antibody and positive controls were provided by the Centers for Disease Control and Prevention (CDC, Atlanta, GA, USA). Mosquitoes were considered positive when the optical density (OD) was higher than the mean plus three standard deviations of the negative controls (OD=0.059).

\section{DNA extraction}

DNA extraction from the salivary glands was performed using DNAzol ${ }^{\oplus}$ (Molecular Research Center, Inc, Cincinnati, $\mathrm{OH}$, USA) according to the manufacturer's instructions. Extracted DNAs were eluted in a final volume of $20 \mu \mathrm{L}$ water and were stored at $-20^{\circ} \mathrm{C}$. DNA extraction was checked for the presence of mosquito DNA by specific PCR for An. gambiae species [21].

Identification of Plasmodium falciparum by multiplex PCR The infection status of $P$. falciparum was determined by multiplex PCR as previously described [7] based on the detection of a Small SubUnit of ribosomal RNA of each Plasmodium species with five primers: universal reverse Plasmodium primer 5'-GTATCTGATCGTCTTCACTCC C-3', P. malariae forward 5'-CGTTAAGAATAAACGC CAAGCG-3', P. falciparum forward 5' - ACAGACGGGT AGTCATGATTGAG-3', $P$. ovale forward 5'-CTGTTC TTTGCATTCCTTATGC-3', and P. vivax forward 5'-CG GCTTGGAAGTCCTTGT-3'. PCR was performed on 5 $\mu \mathrm{L}$ of eluted DNA with the Taq Hot Start Master mix (Qiagen, Valencia, CA, USA) following the manufacturer's instructions. PCR amplification was carried out under the following conditions: an initial incubation cycle to activate the enzyme for $45 \mathrm{sec}$ at $95^{\circ} \mathrm{C}$ followed by 43 cycles of amplification involving $45 \mathrm{sec}$ at $95^{\circ} \mathrm{C}, 90 \mathrm{sec}$ at $60^{\circ} \mathrm{C}$ and a final extension of $5 \mathrm{~min}$ at $72^{\circ} \mathrm{C}$.

\section{Quantitative real-time PCR}

qPCR was performed on $1 \mu \mathrm{L}$ of eluted DNA with the EvaGreen ${ }^{\circledR}$ dye (5X HOT Pol EvaGreen ${ }^{\circledR}$ qPCR Mix Plus (ROX), Euromedex, Souffelweyersheim, France) in the 7300 Real-Time PCR System (Applied Biosystems, Foster City, CA, USA). Specific primers used for the qPCR were 5' -TTACATCAGGAATGTTATTGC-3' and 5' -ATATTG GATCTCCTGCAAAT-3' [9,22]. They amplified a 120-bp sequence of the $P$. falciparum cytochrome c oxidase subunit 1 (Cox1) mitochondrial gene. The reaction mixture was prepared following the procedure of Boissière et al [11]. Absolute qPCR was performed following the amplification program of an initial melting cycle for $15 \mathrm{~min}$ at $95^{\circ} \mathrm{C}$ followed by 40 amplification cycles at $95^{\circ} \mathrm{C}$ for $15 \mathrm{sec}$ and $58^{\circ} \mathrm{C}$ for $30 \mathrm{sec}$. The melting temperature was determined using a dissociation curve. Curves were generated after amplification: at $95^{\circ} \mathrm{C}$ for $15 \mathrm{sec}$ (DNA denaturation), at $60^{\circ} \mathrm{C}$ for $30 \mathrm{sec}$ (double stranded DNA), and at $95^{\circ} \mathrm{C}$ for 15 sec (single stranded DNA). Fluorescence was monitored allowing the identification of the specific melting point. As described by Boissière et al [11], standard curves using 3D7 strain DNA were generated from serial dilution methods and resulting in a quantification range of 6 to 60,000 genomes $/ \mu \mathrm{L}$. These standards were used to determine the concentration of sporozoites in the salivary glands of An. gambiae [11].

\section{Statistical analysis}

Statistical analyses were performed using the statistical software R [23], and all differences were considered significant at $\mathrm{P}$ values of $<0.05$. The means of the amplification efficiencies between the standard samples and the salivary gland samples were compared using the MannWhitney-Wilcoxon test. Cohen's kappa co-efficient ( $\mathrm{k}$ ) was calculated to measure the agreement between the qPCR and multiplex PCR. Methods were compared using the McNemar test.

\section{Results}

The detection threshold of the method was determined by using a five-fold serial dilution of genomic DNA isolated from a 3D7 culture of $P$. falciparum, allowing a quantification range from 6 to 60,000 genomes $/ \mu \mathrm{L}$, as previously described [11]. The reproducibility of the test was confirmed by using a composite of 53 standard curves showing a standard deviation $<0.75$ and a regression value equal to 0.998 for the five data points (Figure 1). The means of the amplification efficiencies per amplicon for the cultured parasites and the salivary gland samples were $94.3 \%$ ( \pm $0.6)$ and $94.1 \%( \pm 0.3)$, respectively, and the difference was not significant $(\mathrm{P}=0.065)$. This result showed that the 
prevalence and intensity of infection can be evaluated using this method. Absolute quantification of P. falciparum genomes in Anopheles salivary gland samples was based on the calibration curve (composite of the 53 standard curves) with a detection limit of six genomes/ $\mu \mathrm{L}(120$ sporozoites by pair of salivary glands in this study). Plasmodium falciparum parasitaemia in salivary gland samples reached 9,262 parasites/ $\mu \mathrm{L}$, with an infection mean of 254.5 parasites/ $\mu \mathrm{L}$ (95\% CI: 163.5-345.6). This result showed an heterogeneity in the Plasmodium infection intensity among mosquitoes, as observed in the salivary glands. For the first time, the optimized qPCR enabled specific detection and quantification of total Plasmodium parasitaemia (genome $/ \mu \mathrm{L}$ ) in $A n$. gambiae salivary glands.

The prevalence of $P$. falciparum was assessed on DNA extracted from the salivary glands of 364 An. gambiae using qPCR and multiplex PCR. The qPCR revealed 276 positive (76\%) and 88 negative (24\%) salivary glands for P. falciparum, whereas the presence of Plasmodium DNA was found in 217 (60\%) salivary glands by multiplex PCR (Table 1). The statistical analysis showed that differences obtained by both methods were significant (McNemar test: multiplex PCR vs qPCR, P <0.001). The 217 positive salivary glands with multiplex PCR were confirmed as positive with qPCR. Among the 147 negative salivary glands detected with multiplex PCR, 88 were also negative with qPCR and 59 were identified as positive. The $\mathrm{qPCR}$ method presented high values of sensitivity of $100 \%\left(\mathrm{Se}=(217 / 217)^{*} 100\right)$ and specificity of $60 \%(\mathrm{Sp}=(88 / 147) * 100)$ when compared to the multiplex PCR, considered here as the reference test. The agreement between qPCR and multiplex PCR was "substantial" ( $\kappa=0.63$ and $P<0.001)$. In the field and especially in the context of malaria eradication or low transmission, the number of sporozoites in salivary glands could be very low and multiplex PCR may not be sensitive enough to detect low infection rates. Furthermore, this method requires a high amount of DNA template and therefore it seems unsuitable for investigating infection in mosquito salivary glands. This may explain the low positivity rate detected in the present study (59\%). Moreover in Plasmodium spp, Cox1 mitochondrial gene is present in higher quantity than the SSU rRNA gene. Indeed, mitochondrial DNA is composed to approximately 20 copies per cell [24], whereas the SSU rRNA genes are presented in 4-8 copies [25]. Consequently, the use of the Cox1 gene for the qPCR increases its specificity. qPCR, known for its sensitivity and for the small amount of DNA required, thus seemed a feasible way to detect Plasmodium in Anopheles salivary glands. Using this technique, a 1.25-fold higher prevalence rate of $P$. falciparum infection compared to the multiplex PCR and a detection limit of six sporozoites/ $\mu \mathrm{L}$ were observed. Interestingly, false-negative samples determined by multiplex PCR were detected as positive using qPCR. In addition, this method estimates the Plasmodium intensity level in contrast to multiplex PCR, even in very small biological samples like the single pair of salivary glands used here. This method could open the way for determining the relationship between the sporozoite load in salivary glands and the infectiousness of the Anopheles mosquito. However, this qPCR approach identified only $P$. falciparum species, in contrast to multiplex PCR. Although P. falciparum is the species causing the majority of clinical cases of malaria in Africa, a recent study in rural Benin has shown that $P$. faciparum accounted for $91 \%$ of the malaria infections,

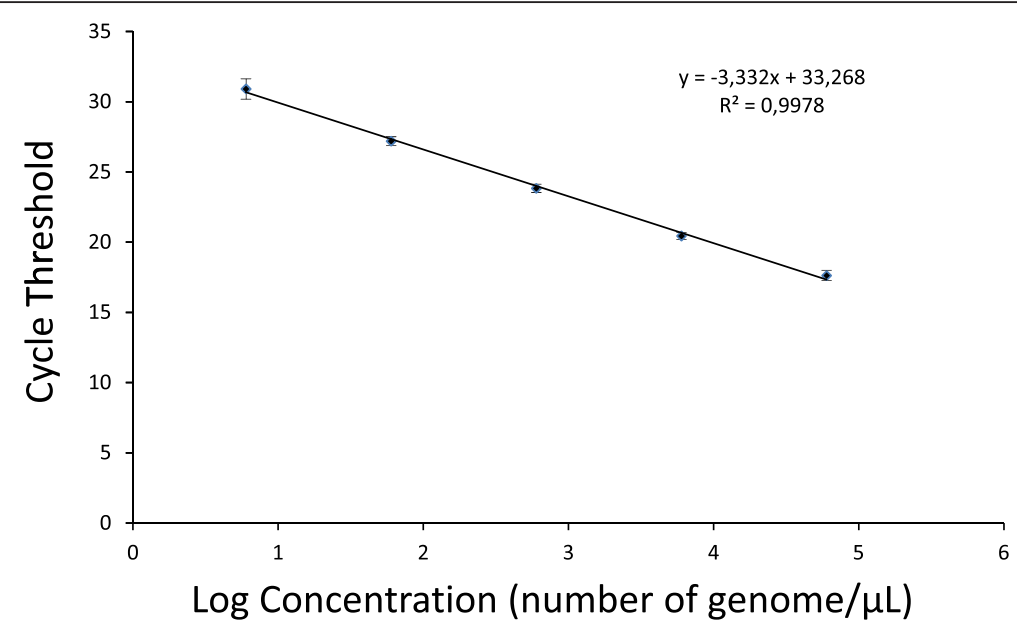

Figure 1 Standard curve of qPCR using serial dilutions of DNA from cultured parasites. Calibration curve was generated using 53 calibrations curves. The curve is based on the known DNA concentration (genomes/ $\mu \mathrm{L}$ ) and shows the reproducibility. Error bars show the standard deviation for each DNA standard from 6 to 60, 000 genomes/ $\mu \mathrm{L}$ [11]. (c) Boissiere et al [11]. 
Table 1 Comparison of qPCR and multiplex PCR techniques for detection of Plasmodium falciparum sporozoites in salivary glands of Anopheles gambiae

\begin{tabular}{|c|c|c|c|c|c|c|}
\hline Salivary glands samples & qPCR positive & qPCR negative & Total & Sensitivity & Specificity & Kappa (к) \\
\hline PCR positive & 217 & 0 & $217(60 \%)$ & $100 \%$ & $60 \%$ & 0.63 \\
\hline PCR negative & 59 & 88 & $147(40 \%)$ & & & \\
\hline Total & $276(76 \%)$ & 88 (24\%) & 364 (100\%) & & & \\
\hline
\end{tabular}

McNemar test: qPCR vs multiplex PCR, $\mathrm{P}<0.001$.

evaluated by thick blood smears. Mixed infections with $P$. malariae or P. ovale were also detected at $3 \%$ and $2 \%$ of the tested slides, respectively [26]. A multiplex qPCR was developed to discriminate the four species of Plasmodium in human blood samples [27,28], and one was developed very recently by Sandeu et al in mosquitoes [13]. However, the latter method was performed and optimized using a duplex qPCR on the head-thorax of mosquitoes, consequently using DNA from both the circulating sporozoites and those in the salivary glands [13].

Some multiplex qPCR assays have also used the EvaGreen ${ }^{\circledR}$ dye, as it was done in the present study $[29,30]$. Therefore, it seems possible to adapt the present qPCR method so as to carry out multiplex qPCR detection of the four species of Plasmodium. Evagreen ${ }^{\bullet}$ dye is a DNA-binding dye with many features that make it superior to the $\mathrm{SYBR}^{\oplus}$ Green I for qPCR [29,31]. Furthermore, this dye is compatible with all common real-time PCR cyclers [32] and is currently about half the price ( $€ 0.16$ per reaction) of the $\mathrm{SYBR}^{\odot}$ Green ( $€ 0.53$ per reaction) commonly used. The duplex qPCR performed by Sandeu et al used the Taqman technique ( $€ 1.12$ per reaction). In conclusion, the qPCR developed here is cost-effective and therefore suitable for large field studies. It is also cheaper than the multiplex PCR ( $€ 1.60$ per reaction).

Detection of the presence of the Plasmodium parasite by CSP-ELISA was also tested on the head-thorax carcasses of the same mosquitoes without salivary glands, thus detecting only circulating sporozoites. A total of 302 mosquitoes were found to be $P$. falciparum positive (range OD: from 0.164 to 2.420 ) (Table 2). The results of the CSP-ELISA showed that a higher number of positive mosquitoes (83\%) were detected compared to multiplex
PCR (60\%) and qPCR (76\%). The statistical analysis revealed statistically significant differences between the three methods (McNemar test: CSP-ELISA vs qPCR, P $<0.001$; CSP-ELISA vs PCR, $\mathrm{P}<0.001$ ) (Table 2). Of the 302 Plasmodium-infected head-thorax-carcasse samples, 261 were found to be positive while 41 samples were negative using the GPCR method. According to these results, $11.2 \%$ of the mosquitoes were found to be Plasmodium positive in the head-thorax-carcasses but not in the salivary glands, meaning that circulating sporozoites can be detected using CSP-ELISA even in non-infective mosquito. This finding is in accordance with other studies $[2,33,34]$ showing that the CSP-ELISA assay (performed on head-thorax including salivary gland) overestimates the sporozoite rate in mosquitoes by detecting circulating sporozoites. Indeed, parasites covered by CSP, spread into the haemolymph for two to three days before they reach the salivary glands [35]. Moreover, it has been shown that only $10-20 \%$ of sporozoites reach the salivary glands [36-38] and that some mosquitoes could be refractory to the entrance of sporozoites in salivary glands [39]. Consequently, CSP-ELISA, which is routinely used in the field, detects infected mosquitoes but not necessarily the infective ones.

\section{Conclusion}

Estimation of malaria transmission requires sensitive and specific tools for the evaluation of infective mosquitoes, i e, detection of sporozoites in Anopheles salivary glands. This study showed that real-time quantitative PCR can be used to detect and quantify sporozoites of wild P. falciparum in the salivary glands of An. gambiae. This qPCR can be performed on small samples such as the DNA of P. falciparum sporozoites extracted from a

Table 2 Comparison of CSP-ELISA with qPCR and multiplex PCR for detection of Plasmodium falciparum sporozoites

\begin{tabular}{llll}
\hline & CSP-ELISA positive & CSP-ELISA negative & Total \\
\hline qPCR positive & 261 & 15 & $276(76 \%)$ \\
qPCR negative & 41 & 47 & $88(24 \%)$ \\
Total & $302(83 \%)$ & $62(17 \%)$ & $364(100 \%)$ \\
PCR positive & 211 & 6 & $217(60 \%)$ \\
PCR negative & 91 & 56 & $147(40 \%)$ \\
Total & $302(83 \%)$ & $62(17 \%)$ & $364(100 \%)$ \\
\hline
\end{tabular}

McNemar test: CSP-ELISA vs qPCR, $P<0.001 ;$ CSP-ELISA vs PCR, $\mathrm{P}<0.001$.

CSP-ELISA was performed on head-thorax-carcasses, and qPCR and multiplex PCR were performed on salivary glands DNA. 
single pair of salivary glands of An. gambiae with a sensitivity of six genomes $/ \mu \mathrm{L}$. In the present study, the realtime quantitative PCR was compared for the first time with multiplex PCR and CSP-ELISA methods.

qPCR is highly sensitive but more specific than multiplex PCR. Moreover, qPCR with EvaGreen ${ }^{\circledR}$ dye is reliable, reproducible, and cost-effective. This method is feasible for evaluating the $P$. falciparum infection rate in the salivary glands and it can lead to an accurate estimation of the risk of transmission in field settings, which were overestimated by CSP-ELISA. Improving the estimation of the EIR with this method could have significant implications on vector control strategies and on the evaluation of their effectiveness.

\section{Competing interests}

The authors declare that they have no competing interests.

\section{Authors' contributions}

$A M, A B, I M$ and $S C$ conceived and designed the experiments. AM, AB, MTT and $I M$ carried out the experiments. $A M$ and $A B$ analysed the data. FR, PHAA and IM contributed reagents/materials/analysis tools. AM, AB, AP and SC wrote the paper. All authors read and approved the final manuscript.

\section{Acknowledgements}

We thank Antoine Berry at Service de Parasitologie-Mycologie, Centre Hospitalier Universitaire de Toulouse, Hôpital Rangueil, (Toulouse, France) for the parasite culture and M.N. Lacroix at Laboratoire de lutte contre les insectes nuisibles (Montpellier, France). We are grateful to volunteers from Mfou primary schools and their parents or guardians for participating in this study, to the medical team from the Mfou hospital for assistance in the field, and to the technical staff of the OCEAC for $P$. falciparum infections. We are particularly grateful to Etienne Onana from the OCEAC for mosquito rearing and salivary glands dissections.

This work was supported by funds from the Institut de Recherche pour le Développement (IRD) and the European Community's Seventh Framework Programme (FP7) (grant agreement N²42095, EviMalaR). AM was supported by an EviMalaR scholarship. The funders had no role in study design, data collection and analysis, decision to publish, or preparation of the manuscript.
\end{abstract}

\section{Author details}

'Laboratoire MIVEGEC (UMR IRD 224 CNRS 5290 UM1-UM2), 911 Av. Agropolis, 34394 Montpellier Cedex 5, France. ' Laboratoire de Recherche sur le Paludisme, Organisation de Coordination pour la lutte contre les Endémies en Afrique Centrale, BP288 Yaoundé, Cameroon. ${ }^{3}$ Centre de Recherche Entomologique de Cotonou, Ministère de la Santé, Cotonou, Bénin.

Received: 18 March 2013 Accepted: 4 June 2013

Published: 2 July 2013

\section{References}

1. MacDonald G: The epidemiology and control of malaria. Oxford University Press 1957:201.

2. Fontenille D, Meunier JY, Nkondjio CA, Tchuinkam T: Use of circumsporozoite protein enzyme-linked immunosorbent assay compared with microscopic examination of salivary glands for calculation of malaria infectivity rates in mosquitoes (diptera: culicidae) from cameroon. J Med Entomol 2001, 38:451-454.

3. Burkot TR, Williams $\lrcorner \mathrm{L}$, Schneider I: Identification of Plasmodium falciparum-infected mosquitoes by a double antibody enzyme-linked immunosorbent assay. Am J Trop Med Hyg 1984, 33:783-788.

4. Vaughan JA, Noden BH, Beier JC: Population dynamics of plasmodium falciparum sporogony in laboratory-infected Anopheles gambiae. J Parasitol 1992, 78:716-724.

5. Zaman S, Tan L, Chan HH, Aziz L, Abdul-Samat S, Wahid R, Kamal A, Ahmed M, Zaman V: The detection of Plasmodium falciparum and $P$. Vivax in
DNA-extracted blood samples using polymerase chain reaction. Trans $R$ Soc Trop Med Hyg 2001, 95:391-397.

6. Fabre R, Berry A, Morassin B, Magnaval JF: Comparative assessment of conventional PCR with multiplex real-time PCR using SYBR green I detection for the molecular diagnosis of imported malaria. Parasitology 2004, 128:15-21.

7. Padley D, Moody AH, Chiodini PL, Saldanha J: Use of a rapid, single-round, multiplex PCR to detect malarial parasites and identify the species present. Ann Trop Med Parasitol 2003, 97:131-137.

8. Swan H, Sloan L, Muyombwe A, Chavalitshewinkoon-Petmitr P, Krudsood S, Leowattana W, Wilairatana P, Looareesuwan S, Rosenblatt J: Evaluation of a real-time polymerase chain reaction assay for the diagnosis of malaria in patients from thailand. Am J Trop Med Hyg 2005, 73:850-854.

9. Bourgeois N, Boutet A, Bousquet PJ, Basset D, Douard-Enault C, Charachon S, Lachaud L: Comparison of three real-time PCR methods with blood smears and rapid diagnostic test in plasmodium sp. Infection. Clin Microbiol Infect 2010, 16:1305-1311.

10. Bell AS, Ranford-Cartwright LC: A real-time PCR assay for quantifying Plasmodium falciparum infections in the mosquito vector. Int J Parasitol 2004, 34:795-802.

11. Boissière A, Gimonneau G, Tchioffo MT, Abate L, Bayibeki A, Awono-Ambéné $\mathrm{PH}$, Nsango SE, Morlais I: Application of a qPCR assay in the investigation of susceptibility to malaria infection of the $\mathrm{M}$ and $\mathrm{S}$ molecular forms of $\mathrm{An}$. Gambiae s.s. In Cameroon. PLoS One 2013, 8:e54820.

12. Vernick KD, Keister DB, Toure A, Toure YT: Quantification of Plasmodium falciparum sporozoites by ribosomal RNA detection. Am J Trop Med Hyg 1996, 54:430-438.

13. Sandeu MM, Moussiliou A, Moiroux N, Padonou GG, Massougbodji A, Corbel $\checkmark$, Tuikue Ndam N: Optimized pan-species and speciation duplex real-time PCR assays for Plasmodium parasites detection in malaria vectors. PLoS One 2012, 7:e52719.

14. Mendes AM, Awono-Ambene PH, Nsango SE, Cohuet A, Fontenille D, Kafatos FC, Christophides GK, Morlais I, Vlachou D: Infection intensity-dependent responses of Anopheles gambiae to the African malaria parasite Plasmodium falciparum. Infect Immun 2011, 79:4708-4715.

15. Bousema T, Dinglasan RR, Morlais I, Gouagna LC, van Warmerdam T, AwonoAmbene PH, Bonnet S, Diallo M, Coulibaly M, Tchuinkam T, Mulder B, Targett G, Drakeley C, Sutherland C, Robert V, Doumbo O, Touré Y, Graves PM, Roeffen W, Sauerwein R, Birkett A, Locke E, Morin M, Wu Y, Churcher TS: Mosquito feeding assays to determine the infectiousness of naturally infected Plasmodium falciparum gametocyte carriers. PLoS One 2012, 7:e42821.

16. Mitri C, Thiery I, Bourgouin C, Paul RE: Density-dependent impact of the human malaria parasite Plasmodium falciparum gametocyte sex ratio on mosquito infection rates. Proc Biol Sci 2009, 276:3721-3726.

17. Nsango SE, Abate L, Thoma M, Pompon J, Fraiture M, Rademacher A, Berry A, Awono-Ambene PH, Levashina EA, Morlais I: Genetic clonality of Plasmodium falciparum affects the outcome of infection in Anopheles gambiae. Int J Parasitol 2012, 42:589-595.

18. Harris C, Lambrechts L, Rousset F, Abate L, Nsango SE, Fontenille D, Morlais I, Cohuet A: Polymorphisms in Anopheles gambiae immune genes associated with natural resistance to Plasmodium falciparum. PLoS Pathog 2010, 6:e1001112

19. Mendes AM, Schlegelmilch T, Cohuet A, Awono-Ambene P, De lorio M, Fontenille D, Morlais I, Christophides GK, Kafatos FC, Vlachou D: Conserved mosquito/parasite interactions affect development of plasmodium falciparum in Africa. PLOS Pathog 2008, 4:e1000069.

20. Wirtz RA, Zavala F, Charoenvit Y, Campbell GH, Burkot TR, Schneider I, Esser KM, Beaudoin RL, Andre RG: Comparative testing of monoclonal antibodies against Plasmodium falciparum sporozoites for ELISA development. Bull World Health Organ 1987, 65:39-45.

21. Scott JA, Brogdon WG, Collins FH: Identification of single specimens of the Anopheles gambiae complex by the polymerase chain reaction. Am J Trop Med Hyg 1993, 49:520-529.

22. Elsayed S, Plewes K, Church D, Chow B, Zhang K: Use of molecular beacon probes for real-time PCR detection of Plasmodium falciparum and other plasmodium species in peripheral blood specimens. J Clin Microbiol 2006, 44:622-624

23. RC T: R: a language and environment for statistical computing. Vienna, Austria: R Foundation for Statistical Computing; 2012.

24. Preiser PR, Wilson RJ, Moore PW, McCready S, Hajibagheri MA, Blight K, Strath M, Williamson DH: Recombination associated with replication of malarial mitochondrial DNA. EMBO J 1996, 15:684-693. 
25. McCutchan TF, Li J, McConkey GA, Rogers MJ, Waters AP: The cytoplasmic ribosomal RNAs of Plasmodium spp. Parasitol Today 1995, 11:134-138

26. Damien GB, Djènontin A, Rogier C, Corbel V, Bangana SB, Chandre F, Akogbéto M, Kindé-Gazard D, Massougbodji A, Henry MC: Malaria infection and disease in an area with pyrethroid-resistant vectors in southern benin. Malar J 2010, 9:380.

27. Shokoples SE, Ndao M, Kowalewska-Grochowska K, Yanow SK: Multiplexed real-time PCR assay for discrimination of Plasmodium species with improved sensitivity for mixed infections. J Clin Microbiol 2009, 47:975-980.

28. Rougemont M, Van Saanen M, Sahli R, Hinrikson HP, Bille J, Jaton K: Detection of four Plasmodium species in blood from humans by $18 \mathrm{~S}$ rRNA gene subunit-based and species-specific real-time PCR assays. J Clin Microbiol 2004, 42:5636-5643.

29. Cheng J, Jiang Y, Rao P, Wu H, Dong Q, Wu Z, Ding X, Guo J: Development of a single-tube multiplex real-time PCR for detection and identification of five pathogenic targets by using melting-curve analysis with EvaGreen. Arch Virol 2012.

30. Khan SA, Sung K, Nawaz MS: Detection of aacA-aphD, qacEס1, marA, floR, and tet $A$ genes from multidrug-resistant bacteria: comparative analysis of real-time multiplex PCR assays using EvaGreen $\left(^{\circ}\right)$ and SYBR( $\left(^{\circ}\right)$ green I dyes. Mol Cell Probes 2011, 25:78-86.

31. Eischeid AC: SYTO dyes and EvaGreen outperform SYBR green in real-time PCR. BMC Res Notes 2011, 4:263.

32. Latrofa MS, Dantas-Torres F, Annoscia G, Genchi M, Traversa D, Otranto D: A duplex real-time polymerase chain reaction assay for the detection of and differentiation between Dirofilaria immitis and Dirofilaria repens in dogs and mosquitoes. Vet Parasitol 2012, 185:181-185.

33. Sokhna CS, Diagne N, Lochouarn L, Rogier C, Trape JF, Spiegel A, Fontenille D: [Comparative evaluation of the plasmodial infection of Anopheles using ELISA and dissection. Consequences for the estimation of the transmission of malaria in 1995 in ndiop, Senegal]. Parasite 1998, 5:273-279.

34. Durnez L, Van Bortel W, Denis L, Roelants P, Veracx A, Trung HD, Sochantha T, Coosemans M: False positive circumsporozoite protein ELISA: a challenge for the estimation of the entomological inoculation rate of malaria and for vector incrimination. Malar J 2011, 10:195.

35. Kappe SH, Kaiser K, Matuschewski K: The Plasmodium sporozoite journey: a rite of passage. Trends Parasitol 2003, 19:135-143.

36. Hillyer JF, Barreau C, Vernick KD: Efficiency of salivary gland invasion by malaria sporozoites is controlled by rapid sporozoite destruction in the mosquito haemocoel. Int J Parasitol 2007, 37:673-681.

37. Rosenberg R, Rungsiwongse J: The number of sporozoites produced by individual malaria oocysts. Am J Trop Med Hyg 1991, 45:574-577.

38. Sultan AA, Thathy V, Frevert U, Robson KJ, Crisanti A, Nussenzweig V, Nussenzweig RS, Ménard R: TRAP is necessary for gliding motility and infectivity of Plasmodium sporozoites. Cell 1997, 90:511-522.

39. Sinden RE: Plasmodium differentiation in the mosquito. Parassitologia 1999, 41:139-148.

doi:10.1186/1475-2875-12-224

Cite this article as: Marie et al:: Evaluation of a real-time quantitative PCR to measure the wild Plasmodium falciparum infectivity rate in salivary glands of Anopheles gambiae. Malaria Journal 2013 12:224.

\section{Submit your next manuscript to BioMed Central and take full advantage of:}

- Convenient online submission

- Thorough peer review

- No space constraints or color figure charges

- Immediate publication on acceptance

- Inclusion in PubMed, CAS, Scopus and Google Scholar

- Research which is freely available for redistribution

Submit your manuscript at www.biomedcentral.com/submit
C Biomed Central 